\title{
De Uexküll à Pask: a Conversação aplicada à Processos Digitais de Projeto
}

\author{
From Uexküll to Pask: Conversation applied to Didital Design Process
}

\author{
> Gilfranco Alves \\ Universidade Federal de Mato Grosso do Sul \\ gilfranco.alves@ufms.br
}

\author{
> Anja Pratschke \\ Universidade de São Paulo \\ pratschke@sc.usp.br
}

\begin{abstract}
The paper will present one specific aspect of the PhD research called Cibersemiótica e Processos de Projeto: Metodologia em Revisáo, funded by FAPESP, which in turn is linked to the Nomads.usp research group of the University of São Paulo. The paper discusses the relevance of communication and information management in the digital design processes from the synchronic study of concepts such as feedback loop, control and self-regulation. These concepts are present in both biosemiotic and interactive design of functional cycle proposed in 1934 by biologist Jakob von Uexküll, as in cybernetic development proposed by Gordon Pask in his sophisticated Conversation Theory in the early 1970 's.
\end{abstract}

Keywords: Biosemiotics; Cybernetics; Cybersemiotics; Conversation Theory; functional cycle;

\section{Introdução}

O interesse na produção arquitetônica com mediação digital tem oportunizado constantes atualizaçôes e revisôes nas fundamentaçôes teóricas relacionadas aos processos digitais de projeto, ampliando as possibilidades de colaboraçáo entre diversos campos do conhecimento e consequentemente promovendo a ampliaçáo dos paradigmas ligados à Arquitetura e Urbanismo.

O presente artigo busca colocar em discussão a relevância da comunicação e do gerenciamento da informação nos processos digitais de projeto frente às recentes atribuiçóes de Arquitetos e Urbanistas, e propor uma abordagem para processos digitais de projeto, a partir do estudo e da aplicação de conceitos como feedback loop, controle e auto regulação. Estes conceitos estáo presentes tanto na concepçáo biosemiótica e interativa de ciclo funcional proposto em 1934 pelo biólogo Jakob von Uexküll ${ }^{1}$, como na elaboração cibernética proposta por Gordon Pask ${ }^{2}$ em sua Teoria da Conversaçáo, no começo dos anos 1970.

1 Jacob Johann von Uexküll (Keblaste, Estônia, 8 de setembro de 1864 - Capri, 25 de julho de 1944) foi um biólogo e filósofo estoniano de origem alemã. Foi um dos pioneiros da etologia antes de Konrad Lorenz, e um biólogo com grandes realizaçóes nos campos da fisiologia muscular e cibernética da vida. Porém, sua realizaçáo mais notável foi a noção de Umwelt, o mundo subjetivo da percepção dos animais em relação ao seu meio ambiente. Fonte: http://pt.wikipedia. org/wiki/Jakob_von_Uexk\%C3\%BCll. Acesso em 07/08/2014.

2 Andrew Gordon Pask (28 de junho de 1928 em Derby - 28 de março de 1996 em Londres) foi um ciberneticista Inglês e psicólogo que fez
Também é objetivo do artigo discutir de que forma seria possível habilitar sistemas de desenvolvimento de projeto fechados, ou intuitivos, na medida em que as decisóes tendem a certos níveis de arbitrariedade (e por isso são do tipo top-down), para que se tornem sistemas mais abertos, colaborativos e assim adquiram características de interatividade, a partir de uma abordagem do tipo bottom-up.

Esta ideologia com base colaborativa, por assim dizer, leva em consideração a mediação digital e seus respectivos processos digitais de projeto, e propóe conceitos que podem trazer olhares importantes para a compreensão e potencialização destes processos. Acreditamos que os conceitos recortados possuem aspectos de grande relevância, não só como fundamentação dos fenômenos observados em vários sistemas e em diversos níveis, mas também como potencialização dos processos a serem aplicados em ambientes digitais e híbridos de projeto. Do mesmo modo, as possibilidades estratégicas de aplicação apontam algumas possibilidades que se mostram bastante promissoras, em termos de ampliação dos níveis de interatividade e de colaboração aplicados aos processos digitais de projeto.

Sabemos que existem infinitos modos de se produzir projetos arquitetônicos a partir da mediação digital. Sabemos também, que a enorme gama de possibilidades tecnológicas leva a uma outra infinidade de desenvolvimentos em relação à métodos e estratégias

contribuiçóes significativas para a cibernética, a psicologia instrucional, epistemologia experimental e tecnologia educacional. Fonte: http:// en.wikipedia.org/wiki/Gordon_Pask. Acesso em 15/08/2014. 
que envolvem processos digitais de projeto. Porém partimos da premissa de que determinados conceitos, advindos de outros campos de conhecimento, como por exemplo, a Biologia, a Cibernética e as Ciências Cognitivas, poderiam trazer contribuiçóes valiosas para outras abordagens que visem a expansão dos limites da Arquitetura e Urbanismo, sobretudo, relacionados aos processos digitais de projeto.

\section{0 circulo funcional de Uexküll e a Teoria da Conversação de Pask}

A pesquisa inicial de Jakob von Uexküll tem origem na tarefa biológica de diferenciar os níveis de percepção específicos em relação aos significados que existem entre vegetais e animais: enquanto animais possuem um mundo de entorno perceptivo, as plantas possuem apenas uma espécie de "envelopamento habitacional". (UEXKÜLL, 1984). Esta distinção implica identificar que nos vegetais existe um único órgão encarregado para perceber e definir como utilizar os significados percebidos, enquanto que nos amimais, a tarefa é dividida em dois órgáos, um perceptivo- denominado por Uexküll receptor ou perceptor, e outro operacional - denominado efetor, que precisam cooperar para que o significado incorporado na percepçáo seja utilizado.

De acordo com a teoria de Uexküll, a fórmula simplificada de propor uma relação de contrapontos sígnicos náo é suficiente para transformar objetos do entorno perceptivo de um observador humano em objetos do entorno perceptivo de um animal sob observação. É necessário, segundo o autor, modificar esta relaçáo de modo a habilitá-la a descrever estas diferentes funções, do órgão perceptor e do órgão efetor, assim como a cooperação entre eles. Segundo Thure von Uexküll (1984), filho de Jakob von Uexküll, com este desejo seu pai desenvolveu o diagrama do círculo funcional, o qual além de resolver as questóes relacionadas à sua pesquisa, antecipou em vinte anos a formulação matemática do princípio do feedback proposto por Norbert Wiener em 1943.

Portanto, a teoria biológica de Jakob von Uexküll estuda as capacidades fisiológicas e comportamentais dos animais em termos de relaçóes significativas entre o sujeito e o ambiente (Umwelt). Todas as experiências sensoriais de organismos levam a açôes significativas posteriores, em função de feddback loops e auto-regulaçóes que encaminham para posteriores inputs perceptivos, coordenados em sequências significativas, que Uexküll denominou de ciclo funcional (Figura 1):

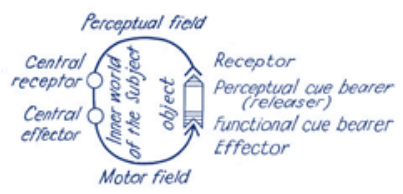

Figura 1: círculo funcional da percepção. Fonte: Uexküll, 1984.

Segundo Sebeok (1989), no modelo de círculo funcional de Uexküll, um signo é recebido de um objeto no campo perceptivo (perceptual field) pelo receptor ou perceptor central (central receptor) e a informação é passada a partir do mundo interno (inner world) para o efetor central (central effector), uma transformação que gera um novo signo que substitui o signo anterior, funcionando como um interpretante mais evoluído, a cada vez que o ciclo se repete. (SEBEOK, 1989. p. 10).

A fórmula ou modelo do círculo funcional torna evidente que este processo não se esgota no acoplamento linear de elos de uma cadeia, mas sim que ele tem uma forma circular: a carga do significado e o utilizador do significado tornam-se elementos de um "campo de força" dentro da qual eles são dirigidos separadamente e ligados entre si novamente, em um movimento de retorno, de retroalimentaçáo do sistema comunicativo, ou seja, de feedback.

Por sua vez, a Teoria da Conversaçáo de Gordon Pask (Figura 2), apresenta um desenvolvimento bastante elaborado sobre as diversas possibilidades de troca de informaçóes e propóe uma estrutura muito pertinente para interaçóes de projeto em sistemas nos quais, humanos, máquinas e ambientes, podem estar engajados em trocas de informação colaborativas. (HAQUE, 2007).

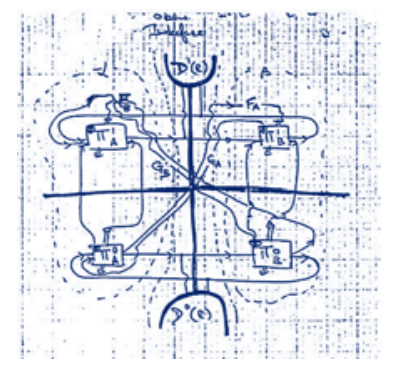

Figura 2: diagrama da teoria da conversação de Pask. Fonte: Haque, 2007.

Para Dubberly ${ }^{3}$ et al. (2009), a conversação é o sistema de comunicação mais evoluído e ocorre quando saída (output) de um sistema de aprendizagem torna-se a entrada (input) para a outro. Além disso, os sistemas podem aprender uns com os outros através da troca de informaçóes de interesses em comum. Eles podem também coordenar objetivos e ações.

Dubberly et al. (2009) indicam o trabalho anterior de Meredith Davis e Richard Buchanan, nos quais o conceito e o potencial da interação são discutidos:

Davis e Buchanan expandiram a forma como olhamos para projeto e sugeriram que a interação entre artefatos e humano seja um critério para avaliar os resultados de todo o trabalho de design. Seu ponto de vista levanta a questão: Seria a interação com um objeto estático diferente de interação com um sistema dinâmico? (DUBBERLY et Al. 2009. p. 01. Tradução Nossa.)

3 Hugh Dubberly é sócio da Dubberly Office Design em San Francisco. Na Apple Computer no final da década de 1980 e no início da década de 1990, Dubberly gerenciou equipes de projeto multifuncionais e mais tarde gerenciou design gráfico e identidade corporativa para a empresa. Em 2000, ele co-fundou o DDO. Fonte: http://designobserver.com/ profile.php?id=299\&name=HughDubberly. Acesso em 16/08/2014. 
Podemos especular que sistemas de conversaçáo sejam capazes de definir metas em comum e projetar meios de alcançá-las. As diferentes possibilidades de troca de informação, apresentados por Dubberly et al. (2009), são muito importantes para a compreensão da Teoria da Conversação. Os autores propóem que uma das maneiras de caracterizar tipos de interaçóes entre sistemas é observar os modos nos quais sistemas podem ser acoplados para interagir: sistemas lineares (ordem zero), sistemas autorreguláveis (primeira ordem) e sistemas que aprendem (segunda ordem), e estes modelos podem ser combinados em seis pares (0-0, 0-1, 0-2, 1-1, 1-2 e 2-2). (DUBBERLY et al. 2009, p. 08).

O sexto e último modelo (2-2) é o que representa a Teoria da Conversação de Pask, e que portanto leva o nome de sistema de conversação (Figura 3). Trata-se de um sistema no qual a saída de um sistema de aprendizado torna-se a entrada de outro. Dentre as várias possibilidades, os autores destacam duas: o caso mais simples é o de interação auto referenciada, no qual o primeiro sistema direciona o segundo, porém o segundo não afeta significativamente o primeiro; a segunda possibilidade se mostra mais interessante, e constitui-se no que Pask chamou de "I/you referenced", onde o segundo sistema recebe a saída do primeiro assim como o primeiro recebe a saída do segundo.

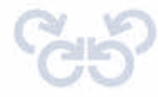

Figura 3: diagrama de um sistema de conversaçáo. Fonte: Dubberly et al. 2009.

Ambos os sistemas possuem a possibilidade de responder um ao outro, ou não. Este tipo de interação é como uma conversação na qual cada sistema sinaliza ao outro, podendo fazer perguntas ou realizar comandos, mas sem a certeza em relação às respostas. Este é o modelo que mais nos interessa, na medida em que define a capacidade de um sistema tornar-se realmente interativo, a partir da habilidade humana da conversaçáo.

Lawson (2011) propóe a ideia de conversa como negociação. Afirma que o processo de projeto pode ser visto essencialmente como uma conversa. O autor aponta Donald Schön como o primeiro a sugerir a ideia de que o projetista "conversa com o desenho”. (SCHÖN, 1983 apud LAWSON, 2011 p. 246). Também destaca a importância das conversas compartilhadas e ensaia algumas possibilidades envolvendo conversas com computadores, segundo seus próprios termos. Porém gostaríamos de destacar seus questionamentos sobre ser possível criar um modelo para o ato de se projetar. O próprio autor acaba por propor um modelo, discutindo questóes relevantes relacionadas ao alcance dos modelos e à atividades e habilidades que deveriam ser contempladas por estes, como por exemplo, "formular, movimentar-se, representar, avaliar e refletir.” (LAWSON, 2011. p. 268).

Mais do que propor um modelo, nossa intenção é discutir possibilidades. Sugerir estruturas para processos digitais de projeto que possam oferecer condiçóes mínimas de organização e entendimento sobre as questóes envolvidas neste tipo de processo.
Porém consideramos fundamental considerar aspectos em aberto, incertezas e níveis de imprevisibilidade em relação às escolhas dos vários atores e os caminhos possíveis em função das particularidades dos sistemas envolvidos.

Sobre a questão da interação, gostaríamos também de fazer alusão à referência que Dubberly et al. (2009) fazem à Meredith Davis e Richard Buchanan, uma vez que apontam que ambos apresentam visóes importantes acerca da interação. Para a primeira, a interação não é algo que surgiu com a mediação digital, uma vez que os livros já convidavam leitores a interagir, e portanto, já possuíam esta qualidade. Para o segundo, interação é uma maneira de propor um framework para a relaçáo entre pessoas e objetos projetados para eles, e, consequentemente, uma forma de propor um framework para a atividade de design. (DUBBERLY et al. 2009).

Segundo o ciberneticista Gordon Pask (1976):

A conversação refere-se a um projeto de longo prazo e suas ramificaçóes intelectuais: em geral, para os artefatos que podem ser produzidos sob condiçōes comparáveis, ao invés de um juntamento de artefatos que foram produzidos $e$ são usados como objetos. A conversação refere-se, em outras palavras, a um meio interpretativo: o sistema de produção concreto ou simbólico em que alunos da escola de arte são capazes de modelar a sua noçáo de realidade. Este universo de interpretação não é dado, como seria em um experimento clássico. Ele é especificado pelos participantes que escolhem propriedades (as construções pessoais ou o núcleo mutuamente aceitável) e depois instancia seus valores. (PASK, 1976. p. 25. Tradução Nossa ${ }^{4}$

Pask reforça a ideia em relação às vantagens de uma abordagem do tipo bottom-up, e que pode ser proporcionada pela conversação. Destaca que aos atores envolvidos no processo deve ser dada a condição de escolha de suas prioridades, definindo o universo de interpretaçóes a partir de construçóes pessoais e do núcleo de questóes que são aceitáveis, de um ponto de vista coletivo. Portanto, por meio da conversação, a definição dos parâmetros pode configurar um processo mais dinâmico e consequentemente, respostas de projeto mais eficientes.

Acreditamos que a Teoria da Conversação, por fazer parte de um conjunto de conceitos cibernéticos, e por consequência também cibersemióticos, pode ser aplicada estrategicamente em uma possível estrutura (framework), que possibilite conceber

$4 \quad$ Do original em Inglês: "The conversation refers to a term project and its intellectual ramifications: in general to artifacts that might be produced under comparable conditions rather than the gaggle of artifacts that were produced and are used as objects. The conversation refers, in other words, to an interpretative medium: the concrete or symbolic production system in which art school students are able to model their notion of reality. This universe of interpretation is not given, as it would be in a classical experiment. It is specified by the participants who choose properties (the personal constructs or the mutually acceptable core) and later instantiate their values." 
possibilidades recursivas de revisão e regulação do processo de projeto de modo significativo.

\section{Considerações finais}

Procuramos com este artigo, demonstrar um enfoque evolutivo dos processos circulares de retroalimentaçáo, partindo do modelo do Círculo Funcional de Jakob von Uexküll e chegando na Teoria da Conversação de Gordon Pask. A estratégia cibernética de utilização de feedback loop, principalmente, é fundamental em qualquer nível de programação que vise controlar e equilibrar sistemas, tais como os sistemas que integram processos digitais de projeto.

Por fim, cabe registrar que em nossa visão, o futuro da arquitetura será participativo e focado em capacitar as pessoas para configurar e melhorar os espaços em que vivem. Um futuro arquitetônico mais interativo tem como principal requisito o aumento do papel dos usuários na concepçáo e no gerenciamento dos espaços arquitetônicos. Consequentemente, esse futuro exige repensar o papel dos arquitetos e urbanistas, e nesse sentido, acreditamos que propor estruturas e estratégias para processos digitais de projeto que contemplem aspectos das teorias aqui relacionadas e brevemente apresentadas, pode trazer importantes contribuiçôes para que este objetivo seja atingido.

\section{Agradecimentos}

Ao Comitê Internacional SIGRADI por fornecer a base para este modelo.

Á FAPESP - Fundação de Amparo à Pesquisa do Estado de São Paulo. (http://www.fapesp.br/)

Ao grupo de pesquisa Nomads.usp. (www.nomads.usp.br).

\section{Referências}

DUBBERLY, Hugh; HAQUE, Usman; PANGARO, Paul (2009) What is Interaction? Are there diferente types? ACM Interactions. Volume XVI.1. Modeling Forum.

HAQUE, U (2007). The Architectural Relevance of Gordon Pask. In: Architectural Design. London. Vol. 77, No4.

LAWSON, Bryan (2011). Como Arquitetos e Designers Pensam. Trad. Maria Beatriz Medina. São Paulo: Oficina de Textos.

PASK, Gordon (1976). Conversation Theory: Applications in Education and Epistemology. Amsterdam: Elsevier.

SEBEOK, Thomas (1989). The Sign \& Its Masters. Lanham: University Press of America.

UEXKÜLL, Thure von. (1984). The Sign Theory of Jakob von Uexküll. In Semiotica: Journal of the International Association for Semiotic Studies. Amsterdam: Mouton. 